\title{
The Function of the Theme Theory in College English Reading
}

\author{
Lv Hongmei, Xiong Shengqi \\ Nanchang Institute of Science \&Technology, Nanchang 330108,China
}

Keywords: Reading ability, English teaching, Theme theory, Quantitative study, Teaching experiment.

\begin{abstract}
In order to improve the students' ability of English reading, this paper proposes a new teaching mode of English reading based on the theme propulsion theory, which analyzes the theme theory of English expression, and summarize the promoting effect of the theme theory on English reading. Through the experiment of English teaching methods, we use the quantitative research method to carry on the experimental study of the relationship between the students' English reading comprehension and the theme theory, the experimental results show that the theory promotes the effect of college English reading. Therefore, in the process of College English teaching, it should be infiltrated into the theme theory, in order to improve students' reading comprehension.
\end{abstract}

\section{Introduction}

Reading ability is one of the major abilities of English learning, which has an important significance for the training of reading skills. In the training of reading skills, most of the teachers use the bottom-up learning method, generally from vocabulary to sentence, and more attention will be placed on the analysis of words and sentences [1-3]. Under the impetus of this teaching mode, the majority of students believe that the accumulation of a certain vocabulary can improve their reading ability, however this method has little effect, students are reduced to fragments on the discourse understanding, and don't understand the author's intention, thus can not be a good grasp of the article from the whole [4,5]. So, how to improve the students' reading ability becomes an urgent problem to be solved, it is a useful attempt, which has an important significance for the study of college English reading teaching.

\section{Overview of the theory}

The small sentence can be divided into the theme and rhema first proposed by Hughes Ma Tai, this theory modifies the subject and the predicate and creatively put forward the theme and rhema to study the information distribution of sentences from the perspective of language function [6]. Later, Hallidy made a further research on the theory, he thought that the theme was the starting point of information, and the rest of the sentence is the rhema, whichwas a new expression information of the sentence, including the author wanted to convey to others all the information, such as:

(1) She (theme) went to go swimming yesterday (rhema).

(2) Yesterday (theme), she went to go swimming(rhema).

In the process of English continuous discourse, the construction of subject has important significance on the whole text . The theme has a reference to the previous in the text, it also acts as the starting point of the sentence, which leads to the new information to promote chapter development according to the form of the author wants to express [7-9]. The relation between the small sentence theme and the change are called the theme propulsion, which is is the key method of the author's organization , but also is the key to the reader's understanding of discourse. At present, the theme propulsion mode is:

A. Constant theme pattern

The Constant theme pattern is a kind of relationship same theme or derivative relationship, and the rhema is different. Assuming that the theme is represented by $T$, and the rhema is represented by $R$, there are 


$$
\begin{aligned}
& \mathrm{T} 1 \rightarrow \mathrm{R} 1 \\
& \mathrm{~T} 2(=\mathrm{T} 1) \rightarrow \mathrm{R} 2 \\
& \mathrm{Tn}(=\mathrm{T} 1) \rightarrow \mathrm{Rn}
\end{aligned}
$$

Fig.1 Constant theme pattern

Fig. 1 shows the constant theme pattern, in which $T n=T n-1(n>1)$, and the model is as follows: last week I(T1) went to the theatre (Rl ). I(T2) got a very good seat (R2). I(T3) didn't enjoy the play(R3).

B. Constant rhema pattern

Constant rhema pattern generally refers to the theme pattern of each sentence that is different, but the rhema pattern of the former sentence is the theme pattern, and the pattern is concentrated. The pattern is shown in Figure 2.

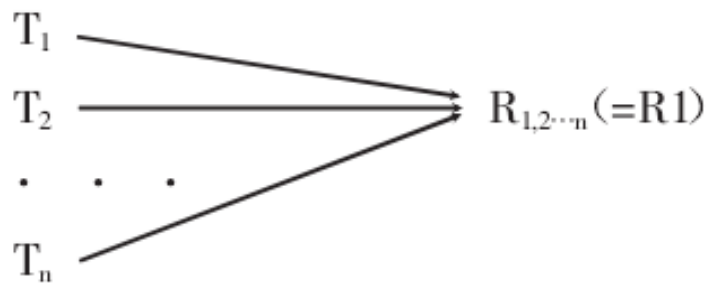

Fig.2 Constant rhema pattern

Fig.2 shows the constant rhema pattern, such as a Chinese (T1) is an Asian (R1), a Japanese (T2) is an Asina (R2) and an Indian (Ts) is an Asina (R3).

C. Cross collusion model

Cross collusion model is that the theme pattern of the former sentence is the rhema pattern of the latter sentence. Through the cross continued, text and paragraphs can proceed smoothly, and the model is shown in Figure 3.

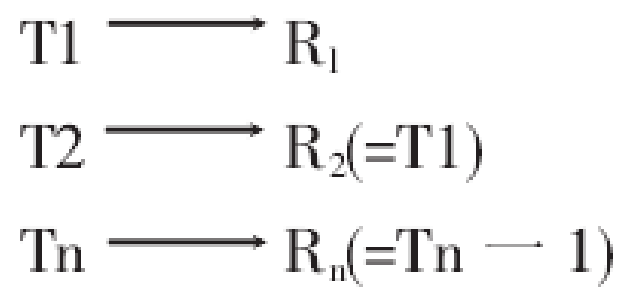

Fig. 3 Cross collusion model

Figure 3 shows the cross collusion model. In order to verify the role of thematic theory on reading, this study adopts quantitative research methods, the subjects selects non English major student in the second grade college, and the use of thematic progression method carries out teaching [10]. Experiment takes the form of group experiments, the relationship between the thematic progression and the reading comprehension level is studied by comparing the control group and the experimental group, which can be applied to the practice of college English teaching.

\section{The Role of Theme Theory on English Reading}

Reading is a kind of written language communication, and readers need to have their own social experience, cognitive structure, interest, cultural literacy and language skills, to extract the information from the reading content and construct the semantic of reading materials [11-13]. However, the use of theme theory can deepen the understanding of discourse. 


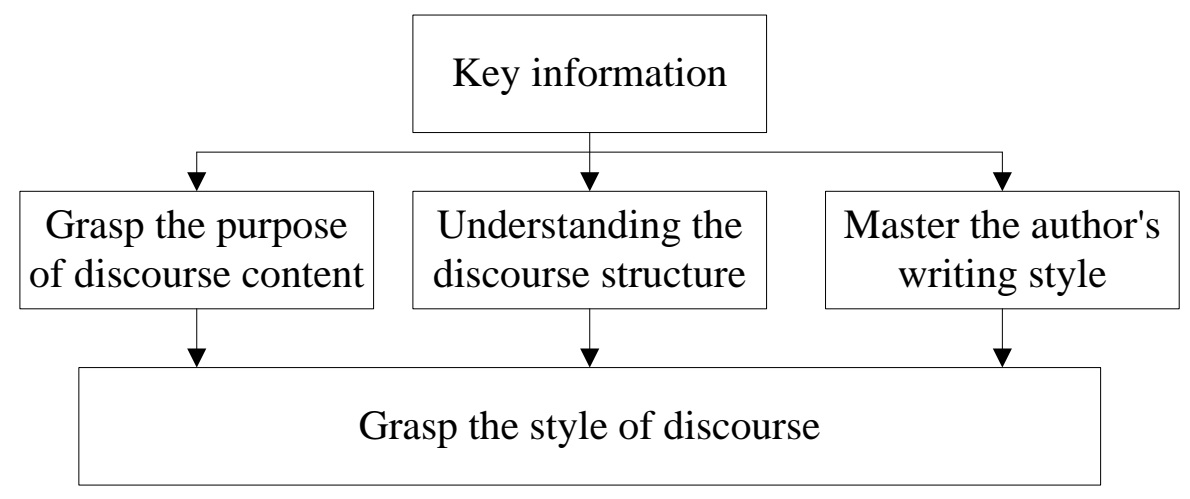

Fig. 4 Schematic diagram of the theme theory on the promoting effect of English

Figure 4 shows the schematic diagram of the theme theory on the promoting effect of English, in which the promoting function of English reading is mainly reflected in five aspects, including the rapid grasp of the discourse content theme, the accurate understanding of the discourse structure, the grasp of the discourse position, the extraction of discourse key information and discourse style grasp.

The rapid grasp of the discourse contents theme. In normal circumstances, different thematic highlights the different components of the sentence in the tex. Due to the different cognitive style, the choice of the theme content is different in the construction of discourse, and the author's content can be reflected by the choice of the theme in English

The accurate understanding of the discourse structure. In the teaching process of English reading, the text structure can be carried out by the thematic progression mode, and the process is simplified, such as the top-down teaching method, first let students assume the content of reading materials, and then to carry on test when reading, which can successfully grasp the author's writing purpose and writing ideas, mastering the structure of the whole text, so as to improve the reading efficiency.

The grasp of the discourse position. In college English reading teaching, we can adopt the thematic progression mode, which makes students grasp the key and the center of the article quickly. Because the choice of the theme position has certain principle, it is bound by the psychological and emotional attitude, and this constraint runs through the whole text. Through the analysis of the theme structure, students can grasp the author's writing position and attitude.

The extraction of discourse critical information. The theme theory is helpful to the students' extraction of key information in the process of English reading. Generally speaking, the new information will be placed at the end of the position, and known information is in the front, which will help students on the extraction of the key information in English reading, thereby improving the efficiency and quality of reading.

The grasp of discourse style. In the whole text of English reading, the theme purpose is to serve the purpose. As the author wants to express his views and opinions, it is a logical relationship between sentences. Generally, the higher frequency is the same pattern of the master, and grasping this model can make readers quickly grasp the style of the text.

The Statistical Analysis of Experimental Results. In order to verify the positive effect of the theme theory on the college English reading, the teaching of College English reading is conducted according to the theory of the master. In reading practice, the experimental group is required to carry out the theoretical analysis of consciousness, because the interest of the teaching experiment is relatively high, so it can stimulate a strong learning interest, and students can actively cooperate. The experimental group and the control group receives the same test questions, and test questions are the four or six test questions. The test results are obtained as shown in Table 1.

Table 1. Test results

\begin{tabular}{|c|c|c|c|c|}
\hline Group & Test number & Mean value & Standard deviation & Mean error \\
\hline Control group & 80 & 49.25 & 14.56 & 1.76 \\
\hline Experience group & 80 & 58.26 & 13.28 & 1.59 \\
\hline
\end{tabular}


Table 1 shows the test result after college reading training obtained by using the consciousness thematic theory, the experimental results can be seen in Table 1that the average scores of the experimental group was higher than control group, thematic theory has a positive promoting effect on reading.

\section{Summary}

By the analysis of the experimental results, it is found that the theme propulsion theory has a positive effect on improving the reading ability of college students. The promoting function of English reading is mainly reflected in five aspects, including the rapid grasp of the theme contents, the accurate interpretation of discourse structure, the grasp of discourse position, the extraction of key information and the grasp of discourse style. Therefore, in the process of English reading teaching , we can have a conscious awareness of the theme propulsion theory to strengthen the students' grasp on the whole text, but also can be the thematic progression theory applied to English writing and listening, improving students' English learning ability.

\section{References}

[1] R. Rui. The matic progression pattern and English Reading Teaching. Journal of Xinyang agricultural college, 2014(9): 152-154.

[2] Y.W. Yang. An empirical study on the teaching strategies of metaphor in College English. Journal of Zunyi Normal University, 2013(5): 84-87.

[3] H.M. Zhu. The application of theme rheme theory in the teaching of English reading. Teaching reform, 2013(3): 180-184.

[4] Y.M. Zhu. A new thinking on improving students' learning interest and motivation in English teaching. China's off campus education, 2014(4): 105-106.

[5] Y. Yang. The advantages and disadvantages of multimedia teaching in English teaching and learning. Journal of Jilin radio and television university, 2013(6): 146-147.

[6] Y.H. Zhang. A study on the dynamic evaluation model of web writing teaching in college English. Foreign language circles, 2014(4): 73-81.

[7] X.Q. Wang. Higher mathematics stratified teaching mode theory and its practice. Jilin education, 2014(11): 20- 21.

[8] D.H. Mao. Research on the implementation of higher vocational mathematic hierarchical teaching. Journal of Chongqing vocational and technical college, 2014,16(4): 43- 44.

[9] F.Y. Li. The application and thinking of multimedia in English teaching. China information technology education, 2014(8): 43-44.

[10] L.J. Song. Analysis of middle school students' psychological characteristics in English teaching. Educational exploration, 2014(3): 55-56.

[11] J. Song. English teaching should pay attention to the students' emotion. Chapter, 2013(5): 92-93.

[12] L. Fu. The use of hierarchical teaching in English teaching. Hope monthly, 2014(8):100-101.

[13] X.Q. Yu. The formation and breakthrough of Matthew effect in basic education. Teaching and management, 2014 (9): 60-61. 